\title{
GAME DYNAMICS IN EDUCATION: EARLY RESULTS AND FUTURE PLANS
}

\author{
Raymond D. Frost, Ohio University, frostR@ohio.edu \\ Erin MacIvor, Ohio University, erinmacivor@yahoo.com
}

\begin{abstract}
This paper is the first in a series that describes the use of game dynamics in an introductory MIS classroom. Here we show how game dynamics can help address two common problems faced by professors in their classroomsassignments turned in late and poor attendance. It introduces a unique learning management system that has built in game dynamics features. We take what are traditionally two of the most dreaded aspects of teaching and turn them into relatively positive experiences for both students and professors. We also suggest how game dynamics might help inspire engaged learning.
\end{abstract}

Keywords: Game dynamics, motivation, information systems education

\section{BACKGROUND}

Conventional wisdom holds that people play video games because they are fun, competitive, or in the case of shooter games, because they satisfy some need for blood lust.

However, a number of researchers have sought to find psychological needs beyond fun that are satisfied by video games. What if those psychological needs are the same needs that are satisfied by engaged learning? If game dynamics align with engaged learning, then bringing game dynamics into the classroom might enhance engaged learning. In other words we might find that we have something to learn from games.

Does this mean that the classroom becomes a game? If by game one means something resembling Second Life then the answer is no. However, there are many shades along the continuum between Second Life and a traditional classroom. Our classroom looks very traditional, yet it uses game dynamics as a behavior motivator.

In fact the real goal of our course is to enhance engaged learning. Engaged learning is thought to heighten student interest and improve learning outcomes. Yet researchers have documented that some aspects of engaged learning are also found within games. Both engaged learning and games encourage discovery, observation, trial and error, and problem solving.

\section{PRIOR RESEARCH}

"Self-determination theory [5] is a macro-theory of human motivation, emotion, and development that takes interest in factors that either facilitate or forestall the assimilative and growth-orientated processes in people" [15]. Researchers in self-determination theory have found that engaged learning satisfies three needs: relatedness, competence and autonomy. People are motived to learn when these needs are met.

The need for relatedness is best defined by Rigby and Ryan [14]. They state, "Relatedness refers to our need to have meaningful connections to others". This need is somewhat emotional, but still requires attention. "In virtually every domain of human endeavor, there is mounting evidence that a network of supportive relationships facilitates an individual's motivation, self-reliance, and relative achievement" [16]. Students who had a strong relatedness to parents and teachers had higher academic achievement [16]. Described in Schlechty [17] and Dickey [8], engaged learning should include an affiliation with others. In this way relatedness helps promote an engaged learning environment.

Engaged learning is also supported when the need for competence is being met. This "refers to our innate desire to grow out abilities and gain mastery of new situations and challenges" [14]. Students want to succeed, but they also want to complete tasks that they consider worth their time. Again this need is described in Schlechty [17] and Dickey [8] through items that should be included in an engaged learning environment. These include focused goals, challenging tasks, clear and compelling standards, protection from adverse consequences for initial failures, and affirmation of performance. 
Volume XII, No. 2, pp 87-94, 2011

The third need is autonomy. According to Rigby and Ryan [14], "autonomy needs reflect our innate desire to take actions out of personal volition, and not because we are 'controlled' by circumstances or by others". One way to create autonomy in the classroom is to provide students with choices and/or creative assignments. Dickey [8] and Schlechty [17] highlight novelty and variety, choice, and authenticity as critical for an engaged learning environment.

Self-determination theory also applies to the video game environment. Ryan and Rigby [14] best describe the connection by stating “Stop thinking 'people play games because they are fun'... set aside the usual ways you think about games". People are willing to play games and spend time trying to succeed at them because their psychological needs are being met. These needs go beyond the content or entertainment value of the games. Of course, these are still factors, but they are not the main idea. The needs being met by video games are once again relatedness, competence, and autonomy. Dickey [8] and Howland [12] describe the different elements in video games that fit into these needs. These are summarized below.

When it comes to relatedness, video game design incorporates a multiplayer design or nonplayer characters. A multiplayer game design has more than one player in the virtual world and allows him or her to interact with all the other players. This encourages teamwork and relationships to develop. If the video game does not have a multiplayer design, it probably has nonplayer characters. These are actors that are programmed into the game, usually with a set number of responses or questions. Most games require interaction with these characters at some point.

In regards to competence, a video game is set up similarly to the engaged learning environment. A successful video game will include focused goals. Whether it is following the narrative or plot of the game, or the chosen character role, goals are established and are designed to progress the game forward. There are also challenging tasks. The challenges are enhanced by the game settings and time limits. The standards are kept clear and compelling. There is protection from adverse consequences through the role playing aspect of the game. Each player will usually choose a character to represent him or her in the game. Finally, performance is affirmed through resource hooks. "A gameplay hook is anything that requires the player to make a decision that relates to the game, and thus keeps them playing" [12]. Specifically, resource hooks are "elements that the player does not directly control in terms of actions, but that affect how the actions work or affect game state" [12]. Example resource hooks include leveling up or health meters.

Finally, the autonomy aspect of video games is in the overall design of the game narrative. This accounts for any choice the player has that can alter the game state. For example, in exploring a video game's virtual world, a player can choose to travel down the path to the left and see where that takes him or her. The player could also choose the path to the right and explore that section. Video game narratives can also allow for players to choose their path through the game. Some games may allow for several endings. Hooks are again used here. In this case, action, tactical, or strategic hooks are used. Action hooks are anything the player does that involves using the controls (i.e. avoiding being shot with missiles from a helicopter) [12]. Tactical and strategic hooks may not be present in every game. These change the way the game is played and usually give the player a temporary advantage (i.e. health boost). Overall the design of the video games through the narrative and hooks satisfy the need for autonomy.

Engaged learning and video games share the satisfaction of same psychological needs; thus there could be benefits to incorporating some of the gaming aspects into education.

\section{SETTING THE STAGE WITH MANY POINTS}

Professors tend to be minimalists when assigning point values in class. It is rare for a class to exceed 1,000 points. However, it quickly became apparent to us that a 5 point bonus did not sound nearly as dramatic as a 50 point bonus. Consequently we scaled up by a factor of ten to 10,000 points. And even this may not be enough in the long term. Games in general offer high point values. It is not uncommon for games to allow players to earn millions of points. More points create a psychological sense of accomplishment. 


\section{DEALING WITH LATE ASSIGNMENTS}

The most professors would prefer that assignments be turned in early or at least on time. On time submissions take less time to process - there is no administrative overhead to retrieve, document, and discount the late submissions. On time submissions are much easier to grade since the grader is in a state of flow while grading.

The two standard solutions to late assignments are zero tolerance and exceptions for valid excuses. However, there are problems with the standard solutions. Zero tolerance does not allow for valid excuses. Furthermore, valid excuses are awkward or difficult to verify. For example, does the professor demand a death certificate when a student reports that they missed a due date because their grandmother died? How does the professor respond when a student claims that Blackboard locked up or shut them out in the minutes prior to the due date? Still another example is the student who claims exemption due to participating in a team or club.

Excuses create the need for a judgment call on the part of the professor as to whether or not the excuses are valid. If excuses are not verified then a student could deceive the professor. This would be unfair to the other students. Also, a potential inequity is created with those students who, perhaps facing similar adversity, were able to complete the assignment on time.

Valid excuses are an administrative headache to track and record. Learning management systems typically do not have smooth mechanisms to track excuses. The lack of a tracking mechanism requires cumbersome improvisation by creating text fields to store the excuse information. Furthermore, the information is not automatically tallied or monitored for abuse.

\section{OUR SOLUTION USING LIVES}

Adopting terminology from games, every student is given three lives at the beginning of the term. A life may be redeemed to turn an assignment in late--no questions asked. Sickness, family emergency, or extracurricular travel are all treated identically — a student must use a life to turn an assignment in late.

The learning management system automatically tracks the late submissions. It also tracks the number of lives remaining. The learning management system allows the professor to set the time frame for late submission. We have it set to 48 hours beyond the due date. Beyond that time frame the system reverts to zero tolerance. The system also reverts to zero tolerance after the lives are exhausted.

Students can earn up to three extra lives (for a total of six) by turning in assignments early. This allows a student to replenish lives lost previously by turning in other assignments early. We have set the definition of early as at least 48 hours early.

However, we would prefer that students not turn in assignments late. Therefore we offer to buy back the lives at the end of the semester for 50 points each or 300 points ( $3 \%$ of their final grade) for a student who ends with all six lives.

The last two weeks of the quarter we have group projects. Therefore, no lives may be earned or redeemed the last two weeks of the quarter.

\section{ATTENDANCE}

Most professors would prefer that students attend every class. Attendance helps the entire class advance at a uniform rate. Attendance helps the professor avoid covering old ground in response to questions.

The standard solutions and their shortcomings are very similar to those of late assignments. The two standard solutions are zero tolerance and exceptions for valid excuses. But zero tolerance does not allow for valid excuses and valid excuses are awkward to verify. For example, does the professor ask for a doctor's note when the student was too sick to leave their dorm room? And what of the student that fights through the illness to attend class?

Tracking valid excuses is difficult and time consuming. It is effectively busy work for the professor. As with tracking late assignments, learning management systems do not offer much help. 
Volume XII, No. 2, pp 87-94, 2011

\section{OUR ATTENDANCE SOLUTION USING AN APPOINTMENT DYNAMIC FROM GAMING.}

Students are rewarded points for each day that they attend class. For example, there are four sessions each weektwo lectures and two labs. Each lecture and/or lab is worth 10 points (out of 10,000) for a total of 40 points in a given week.

Perfect attendance in any given week receives an additional bonus. A student with perfect attendance in a given week receives an additional 20 point bonus for a total of 40 plus 20 or 60 points for the week. Over the course of 10 weeks this could lead to 200 bonus points or $2 \%$ of the student's final grade.

Every student is allowed to miss as many classes as they like-no questions asked. Absences are recorded on a seating chart. There are no excuses accepted for any reason. Students can always make up points lost by achieving perfect attendance in other weeks. The learning management system automatically tracks the absences.

\section{RESEARCH METHODOLOGY}

The game dynamics techniques were applied to four large sections (about 75 students each) of an introductory MIS course offered at a large Midwestern university in the spring quarter of 2011. Each quarter lasts for ten weeks. The course is a required course for all College of Business students and is required by a number of other programs throughout the university. It also serves as an elective for computer literacy.

The course was in other respects identical to the same course offered in the previous quarter (winter 2011). The same professors, text, teaching assistants, content, and assignments were used.

The game dynamics were presented in the syllabus and then a show of hands was solicited to verify that everyone understood the rules. The game dynamics were explained a second time a few weeks into the quarter again soliciting a show of hands for understanding.

As the course progressed the online grade book listed all lives and attendance records "above the fold" of the computer screen. In other words there was no way that a student could avoid seeing their progress on the game dynamics dimensions. See the sample screenshot below.

\begin{tabular}{|c|c|c|c|c|}
\hline Assignment & $\underline{\text { Status }}$ & Due date & Grade & Feedback \\
\hline Life 6 & extra credit & no due date provided & $\cdot$ & \\
\hline Llfe 5 & extra credit & no due date provided & 50 & view feedback \\
\hline Life 4 & extra credit & no due date provided & 50 & view feedback \\
\hline Life 3 & extra credit & no due date provided & * & \\
\hline Life 2 & extra credit & no due date provided & $\cdot$ & \\
\hline Life 1 & extra credit & no due date provided & $\cdot$ & \\
\hline Attendance $3 / 28 \& 3 / 30+$ Bonus Opp. & & no due date provided & $60 / 40$ & view feedback \\
\hline Attendance $4 / 4$ \& 4/6 + Bonus Opp. & & no due date provided & $30 / 40$ & view feedback \\
\hline Attendance $4 / 11$ \& 4/13 + Bonus Opp. & & no due date provided & $10 / 40$ & view feedback \\
\hline Attendance $4 / 18$ \& $4 / 20+$ Bonus Opp. & & no due date provided & $20 / 40$ & view feedback \\
\hline Attendance $4 / 25$ \& 4/27 + Bonus Opp. & & no due date provided & $10 / 40$ & view feedback \\
\hline Attendance $5 / 2 \& 5 / 4+$ Bonus Opp. & & no due date provided & $30 / 40$ & view feedback \\
\hline Attendance 5/9 \& 5/11 + Bonus Opp. & & no due date provided & $0 / 40^{*}$ & \\
\hline Attendance 5/16 \& 5/18 + Bonus Opp. & & no due date provided & $0 / 40^{*}$ & \\
\hline Attendance $5 / 23 \& 5 / 25+$ Bonus Opp. & & no due date provided & $0 / 40^{*}$ & \\
\hline Attendance $6 / 1$ Last day of class + Bonus Opp. & & no due date provided & $0 / 20^{*}$ & \\
\hline Writeup AITP meeting for 100 points Extra Credit & extra credit & $5 / 31$ & * & \\
\hline
\end{tabular}


Volume XII, No. 2, pp 87-94, 2011

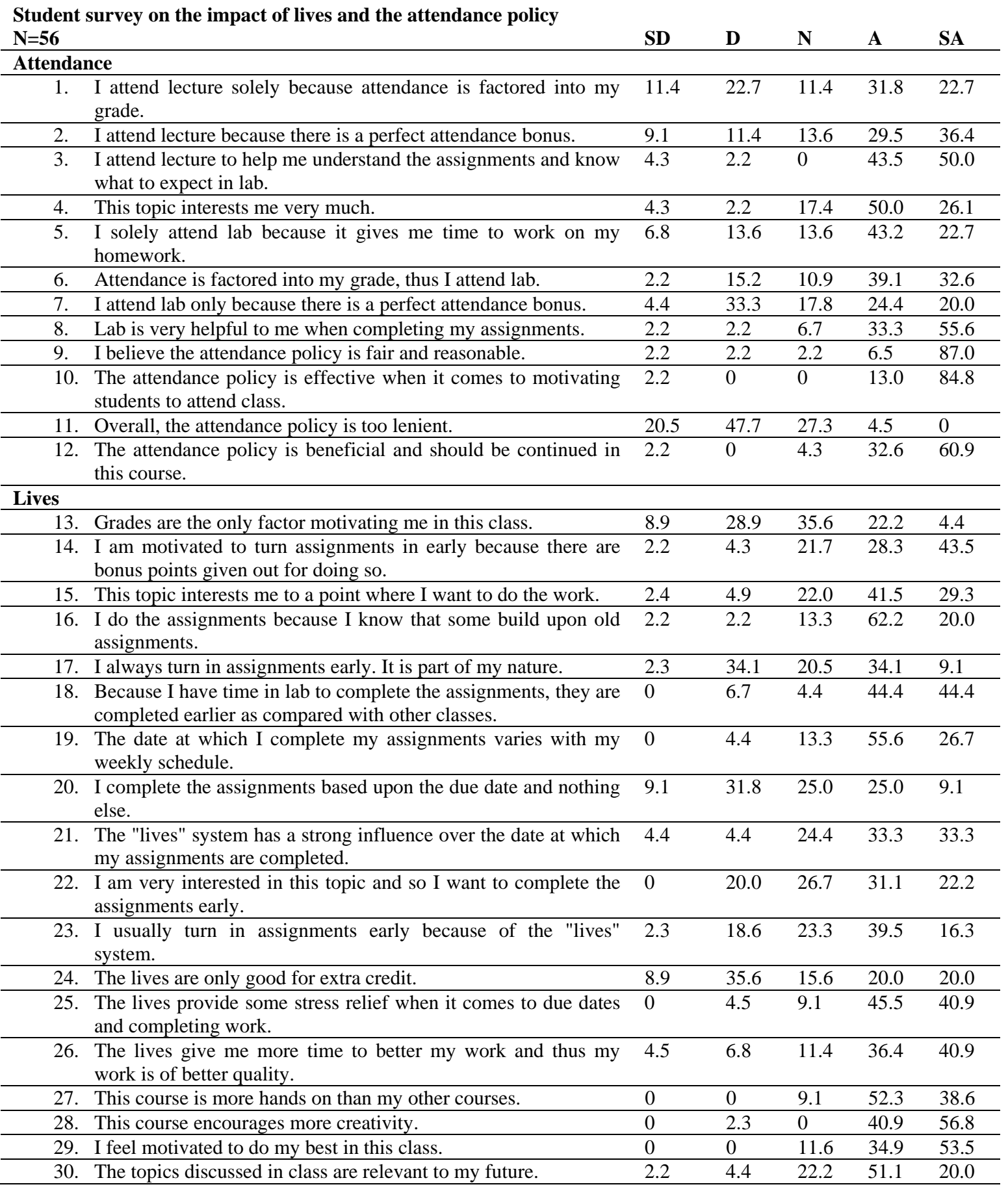

In week 6 two of the sections were given open ended questions in a pilot study to gauge the effects of the game dynamics. These questions included:

1. What motivates you to attend our class sessions?

2. How would you describe the attendance policy?

3. What motivates you to accomplish your work?

4. What influences the date at which you completed your work? 
Volume XII, No. 2, pp 87-94, 2011

5. How would you say the "lives" have affected your performance in the course?

6. Overall, how would you compare this course to other courses you have taken?

Data from the questions were analyzed and coded to develop 30 Likert scale questions to be administered to the control group. The results are shown in the table below:

In addition to perceptions, we also studied actual behavior in the aggregate as compared with the prior quarter. Since enrollment was nearly identical in both quarters we were able to simply count the number of absences and the number of assignments turned in late in each quarter.

\section{RESULTS AND DISCUSSION}

In terms of perception and actual behavior the use of lives would have to be characterized as a success.

Students generally rated the lives system as:

- Very fair

- A stress reliever

- A motivator to perform their best

Student behavior mirrored their perceptions. The number of students turning in assignments early to earn lives increased tremendously. The number of students turning in assignments at the last minute, but on time, decreased dramatically. The number of students turning assignments in late stayed relatively constant.

Faculty and teaching assistants also had a favorable view of the use of lives. Grading became much easier since no appeals on due dates needed to be considered. Both the faculty and TAs also reported finding it less stressful to deliver the news that they were sorry about the problem that the student faced but that it would still cost them a life.

In terms of perception the attendance policy was a success. Students generally rated the attendance policy as:

- Very fair

- A motivator to attend class

- Beneficial

However, student behavior did not mirror the perception on the dimension of the points serving as a motivator to attend class. Absenteeism increased almost 300\%. This completely took the researchers by surprise given the relative ease with which attendance points can be earned. In fact we had expected just the opposite - that every student would bank as many attendance points as possible.

The dichotomy between the perception and the actual behavior may be explained by the fact that only those attending lab actually completed the online survey.

The faculty and teaching assistants liked not having to make judgment calls on absenteeism. They also noted a positive student response to the attendance policy. Nonetheless, they were disappointed by the poor attendance. Future plans call for adjusting the policy to remedy this situation.

\section{DISCUSSION}

While we were disappointed in the level of attendance, we think that we may have accidentally revealed that lives have an intangible value that exceeds their equivalent value in points.

To illustrate this point consider the following. The value of a life is 50 points. The value of missing one day of class is 40 points (lecture 10 points, lab 10 points, and forfeiting the 20 point perfect attendance bonus). Yet while the point values were nearly equivalent, nonetheless students went to great lengths to avoid losing a life but they would willingly sacrifice points to skip class. The lives were so highly valued by students that we observed some bizarre behaviors to preserve them. For example, one student preferred not to turn in an assignment at all rather than 
Volume XII, No. 2, pp 87-94, 2011

lose a life. This would appear to be an irrational decision (or extreme laziness) since the assignment is worth 300 points while the life is only worth 50 points.

We conclude from this that lives have an intangible worth that exceeds their point redemption value. In a way this should not be surprising. For example, gifts are often appreciated more than their cash equivalents. We plan to test this conclusion in our next study by requiring students to forfeit lives to skip classes. Lives will become the singular currency for both late assignments and attendance.

We plan to increase the value of lives further by making it more difficult to earn an extra life. We will require two weeks of perfect attendance to earn a life. Other plans include the creation of a leader board where one is able to compare his or her ranking with that of the rest of the class to be used as a motivational tool.

The lives system could be used in any course in any discipline. While our system tracks lives automatically, nonetheless, the lives could be tracked by hand on a system such as Blackboard.

\section{CONCLUSION}

The primary aim of this paper was to focus on the administrative benefits of using game dynamics in the classroom. However, the long term aim of our research is to heighten engaged learning using game dynamics. We will take tangible steps in that direction when we unveil a leader board. However, there is a hint right now that we are tapping into some engaged learning dimensions. For example, students report a greater sense of autonomy about when they turn in work or come to class. Their level of risk and stress has also been lowered. As for relatedness, one of the class assignments has students collectively build a store to sell iPhone apps. As for competence we maintain clear and compelling standards through a grading system relying on built in rubrics. The system of redeeming lives to turn in late assignments also offers some protection from adverse consequences for those students who might otherwise have submitted a half finished assignment.

Our hope is that the new system will result in more engaged learning and higher grades. We will have more information on this when the quarter concludes and will report back at that time.

\section{REFERENCES}

1. Baumeister, R. F., \& Leary, M. R. (1995). "The need to belong: Desire for interpersonal attachments as a fundamental human motivation”. Psychological Bulletin,

2. Blunt, Richard, (2009) "Do Serious Games Work? Results from Three Studies” eLearn Magazine

3. Csikszentmihalyi, M. (1975). Beyond boredom and anxiety. San Francisco: Jossey-Bass.

4. Deci, E. L. (1975) Intrinsic motivation. New York; Plenum.

5. Deci, E.L and Ryan, Richard M. (2000) "Self-Determination theory and the Facilitation of Intrinsic

6. Motivation, Social Development, and Well-Being”. American Psychologist. 68-78.

7. Deci, E.L.; Ryan, Richard M.; and Williams, Geoffrey C., (2002) "Need satisfaction and the self-regulation of learning”. Elsevier Science Inc.

8. Dickey, Michele D., (2005) "Engaging By Design: How Engagement Strategies in Popular Computer and Video Games Can Inform Instructional Design”. Educational Technology Research and Development

9. Dweck, C. S. (1986). "Motivational processes affecting learning." American Psychologist, 41, 1040-1048.

10. Entertainment Software Rating Board (2011) “How Much Do You Know about Video Games?”

11. http://www.esrb.org/about/video-game-industry-statistics.jsp

12. Howland, G. (2002). Balancing gameplay hooks. In F. D. Laramée (Ed.) Game design perspectives. Hingham, MA: Charles River Media

13. Malone, T. W. (1982). Toward a theory of intrinsically motivating instruction. Cognitive Science 4, 333-369

14. Rigby, Scott and Ryan, Richard M. (2011) Glued to Games. California: ABC-CLIO, LLC

15. Ryan, Richard M and Niemiec, Chistopher P., (2009) "Autonomy, competence, and relatedness in the classroom: Applying self-determination theory to educational practice” Theory and Research in Education. Sage.

16. Ryan , R. M., Stiller, J., \& Lynch, J.H. (1994). Representations of relationships to teachers, parents, and friends as predictors of academic motivation and self-esteem. Journal of Early Adolescence. 
Volume XII, No. 2, pp 87-94, 2011

17. Schlechty, P. C. (1997). Inventing better schools: An action plan for educational reform. San Francisco, CA: Jossey-Bass.

18. Stillwell, Robert. (2011) "Public School Graduates and Dropouts from the Common Core of Data: School Year 2008-09”. National Center for Education Statistics 